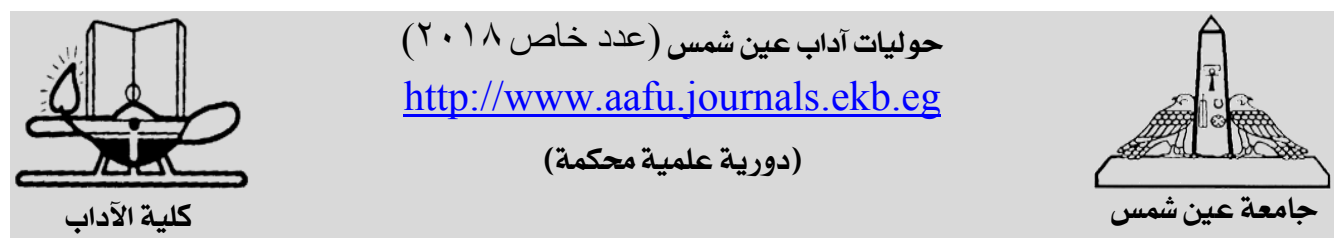

\title{
أبنية الأنعال المتعدية في ديوان فوزي المعلوف
}

أماني أحمد محمود

جامعة عين شمس- كلية الآداب- قسم اللغة العربية وآدابها

يعتمد هذا البحث على وصف أبنية الأفعال المتعديّة في ديوان فوزي المعلوف، وبيان

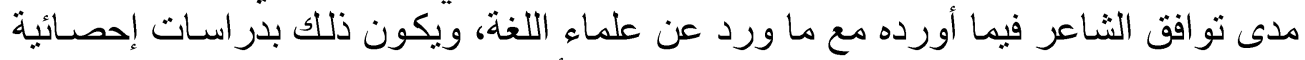

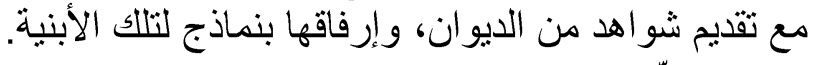
وذللك يصنّف في در اسة:

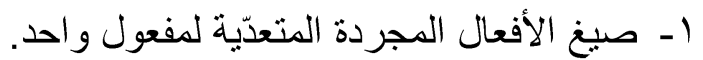

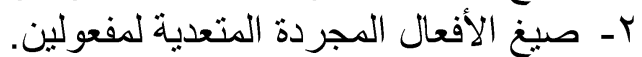

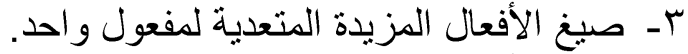
ع- صيغ الأفعال المزيدة المتعدية لمفعولين.

و وأما در اسة صيغ الأفعال المتعدية لثناثة مفاعيل، فلم ثُصنّف مع الصيخ السابقة، لعدم ورودها في ديوان الثاعر . 


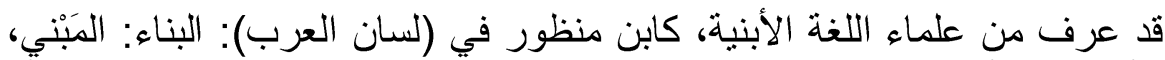

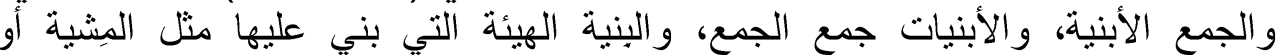
الرّّكبة" (1) هذا من الناحية اللغوية لكلمة البناء.

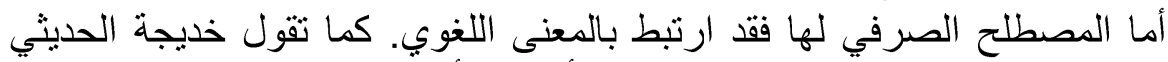

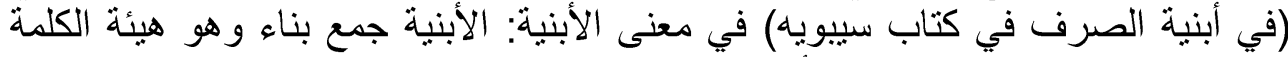

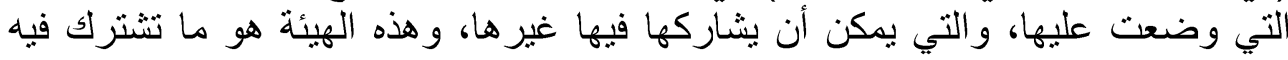

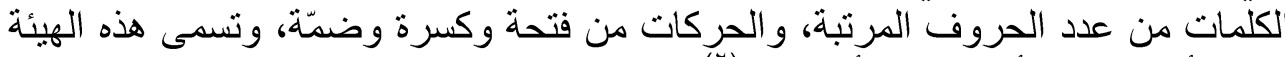

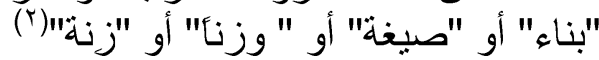

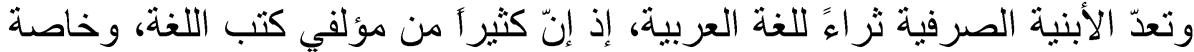

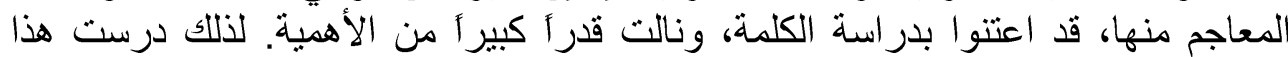

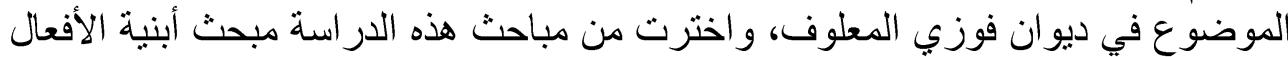

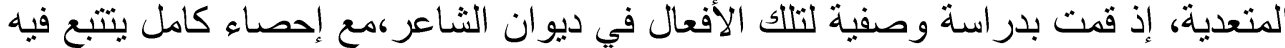
مدى تو افق ما أورده الثاعر من أبنية مع ما ورد عن كتب لبت اللغة.

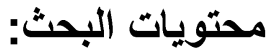

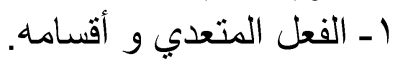

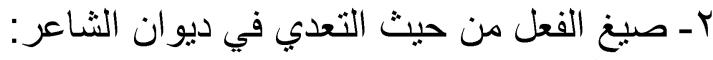
ثُصنّف إلى قسمين:

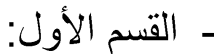
صيغ الأفعال المتعدية لمفعول به واحد.

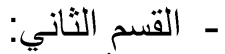
صيغ الأفعال المنعدية لدفعولين.

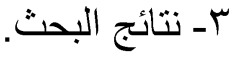




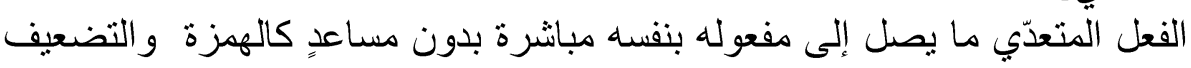

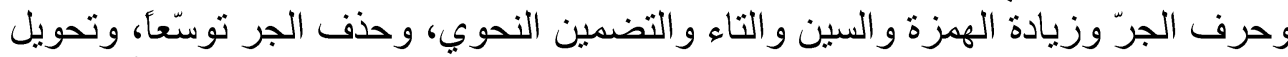

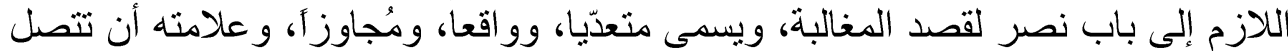

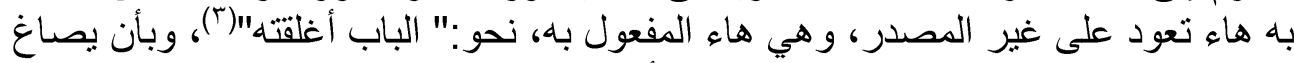

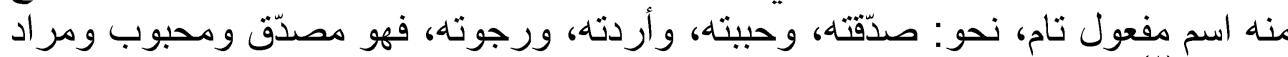

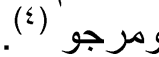

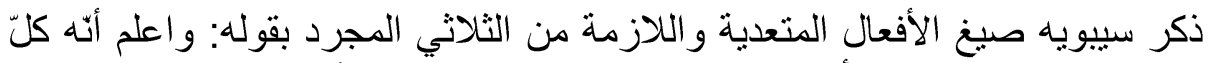

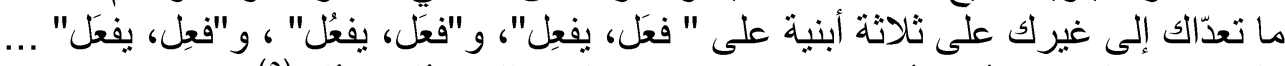

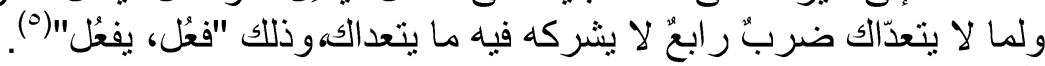

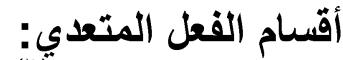

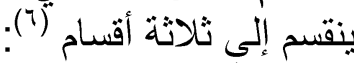

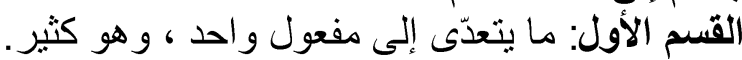

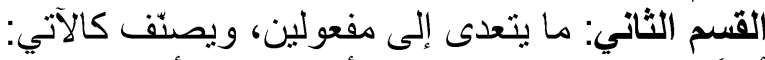

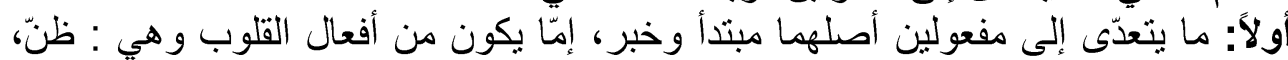

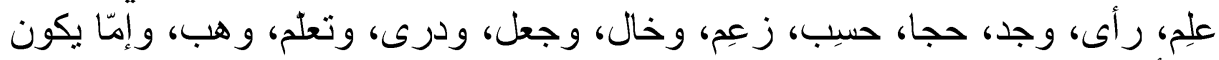

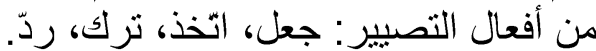

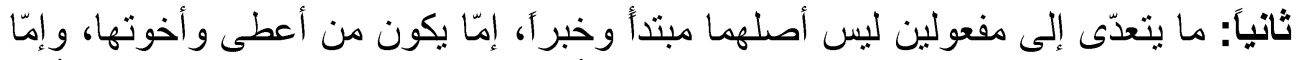

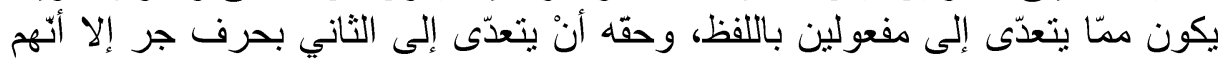

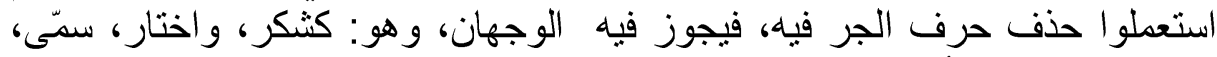

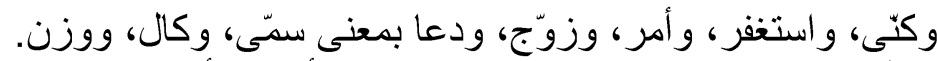

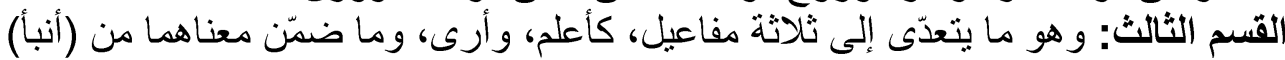

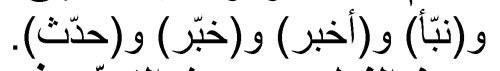

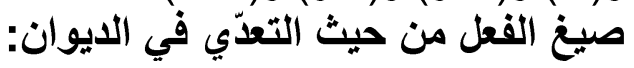

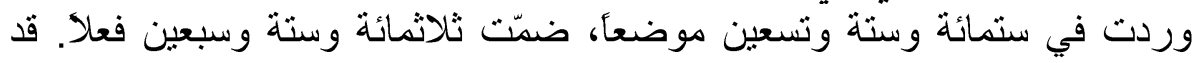

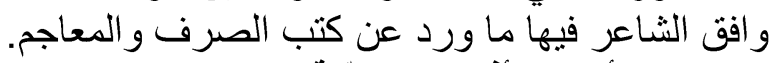

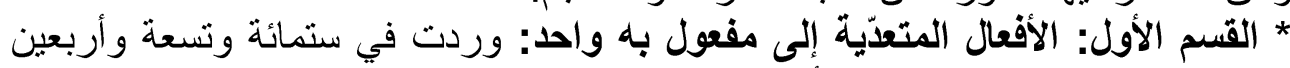

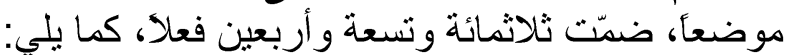

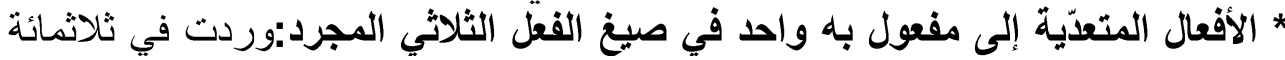

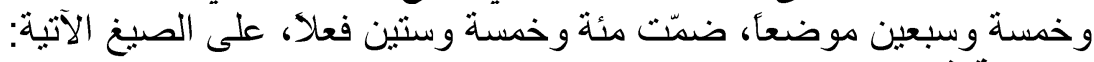

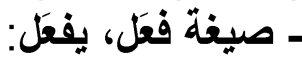

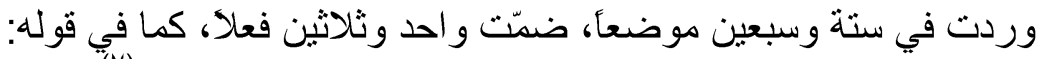

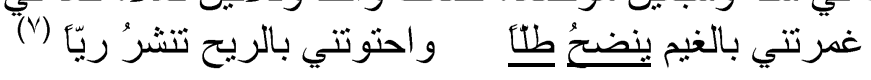


جدول صيغة (فَلَ، يفعَل) المتعدي

\begin{tabular}{|c|c|c|c|c|c|}
\hline الصفحة & 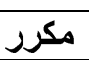 & الفعل & الصفحة & 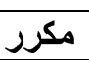 & الفعل \\
\hline 110 & - & منعنا & 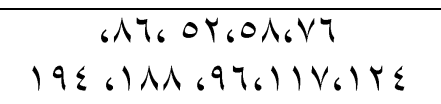 & $\wedge$ & تملا \\
\hline $1 Y \varepsilon$ & - & طعن & 1196006119 & $r$ & 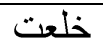 \\
\hline 1KT & - & ذعر & $110617 \leqslant 617 \leqslant 61 Y 0614$ & $\varepsilon$ & تلمح \\
\hline IYT & - & سحق & $17 \wedge 617461.161 \leq \cdot 61 \ldots$ & $\varepsilon$ & نال \\
\hline 1896117 & 1 & وضع & 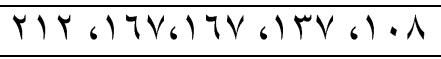 & $\varepsilon$ & يبعث \\
\hline $1 \leq Y, 1 T V$ & 1 & نفع & 104 & - & يرفع \\
\hline
\end{tabular}

استخدم الثاعر الفعل (برَى) في ستة و عثرين موضعاك، كما في قوله:

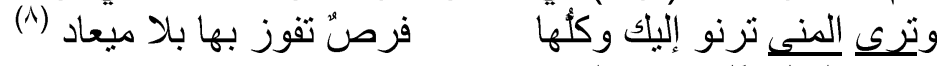

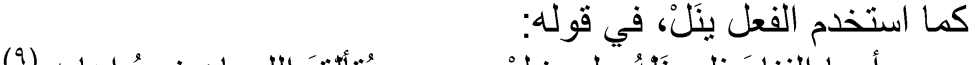

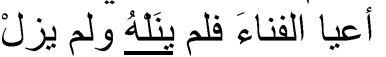
ما حذف لام ماضيه أو أمره:

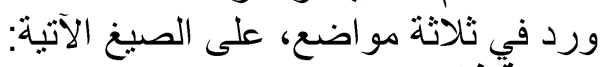

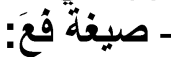
وردت في موضعين، كما في قوله:

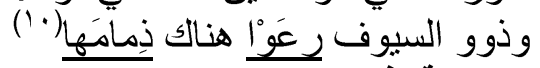

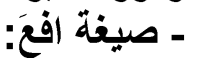
وردت في موضع واعنة واحد، كما في قوله:

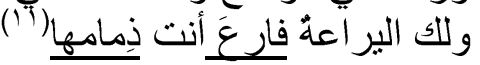

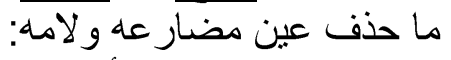

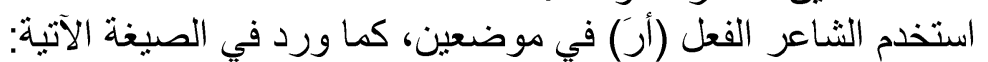

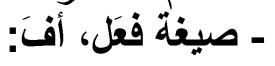

كهذا في الجوّ مابين طيره (r')

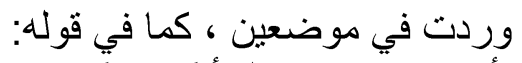

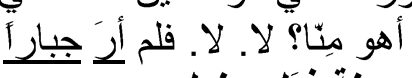

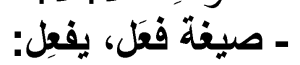
وردت في سبعة وسبعين موضعاك، ضمّّت ستة وأربعين فعلا،كما في قوله:

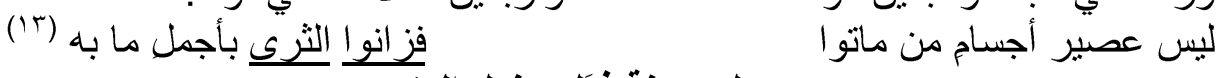
جدول صيغة فعل، يفعِل المتعدي فزئر

\begin{tabular}{|c|c|c|c|c|c|}
\hline الصفحة & مكرر & الفعل & الصفحة & مكرر & الفعل \\
\hline $1 \leqslant \varepsilon$ & 1 & زان & $\begin{array}{l}.0 .61 Y 7 \\
111\end{array}$ & r & نزعت \\
\hline $\begin{array}{l}61 T \varepsilon 61 T \varepsilon 671670 \\
194610 V_{6} 1916191\end{array}$ & $\bar{V}$ & يعرف & Or & - & كوى \\
\hline 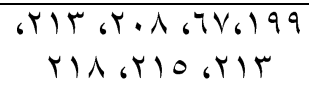 & 7 & حمل & 194.08 & $T$ & يطوي \\
\hline Vo & - & فرَ & 00 & - & تضرب \\
\hline$V_{7}$ & - & يقذف & 07 & - & عقدت \\
\hline $1916 \times 9$ & 1 & غسلت & 7. & - & حدّ \\
\hline
\end{tabular}




\begin{tabular}{|c|c|c|c|c|c|}
\hline 97 & - & نروي & 71 & - & ضلّ \\
\hline $\begin{array}{c}61796 \times 961.76177 \\
19 .\end{array}$ & $\varepsilon$ & يسكب & 71 & - & يحكي \\
\hline- & - & - & 11. & - & عصى \\
\hline
\end{tabular}

ما حذف فاء مضنار عه:

استخدم الثاعر الفعل (تصفِل) في موضع واحدة، كما ورد في الصبغة الآتية:

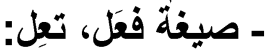

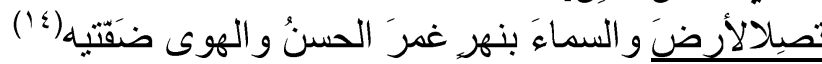

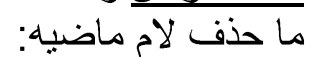

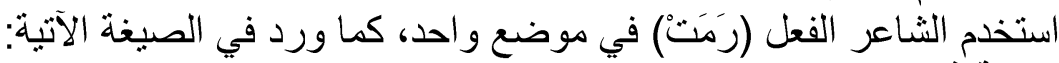

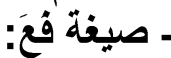

سهمأ فأقعدها الهوى و أقامها(10)

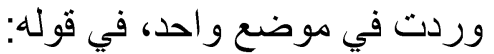

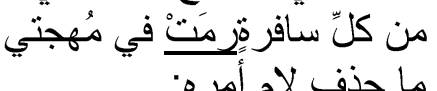

استخدم الثاعر الفعل (ارو) في موضع واحد، كما ورد في الصبيغة الآتية:

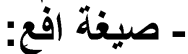

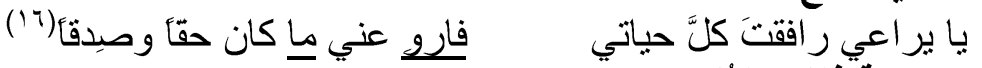

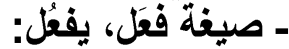

وردت في مئة وثمانية و عشرين موضعاك، ضمّت اثثين وستين فعلا، كما في قوله:

نسمة الثعر أنتي، فيه تبشينين

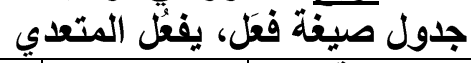

\begin{tabular}{|c|c|c|c|c|c|}
\hline الصفحة & مكرر & الفعل & الصفحة & مكرر & الفعل \\
\hline$\left.V \varepsilon 67_{6}\right) 7 V$ & $r$ & حال & $O V_{6} \leqslant 0$ & r & بث \\
\hline $1 \mathrm{VA} .7 \mathrm{~V}$ & 1 & حبلك & $\varepsilon 7$ & - & ركن \\
\hline 71.71 & 1 & يعقب & $\begin{array}{l}6 \Sigma \Lambda_{6} T \cdot 6 V \cdot \\
\left.Y \cdot V_{6}\right) \leq q\end{array}$ & $\varepsilon$ & غمر \\
\hline $1 Y \cdot 6 I I V 6$. & r & تنشر & $r \cdot V 60.619 r$ & Y & نقل \\
\hline IST GITV 6VT & r & ينفع & 01 & - & يخُط \\
\hline$V(4) 7 \leqslant 6199$ & $r$ & يقود & 119 & - & يذوق \\
\hline $1 Y A 67$ & 1 & داس & or & - & فلكّ \\
\hline $1 \mathrm{VV} 61176 \mathrm{VA}$ & $r$ & رمق & 117.00 & 1 & شق ش \\
\hline 19 & - & سكن & 110690607 & r & مدّ \\
\hline 111 & - & نققو & 01 & - & نحشّد \\
\hline $111.90 .9 \mathrm{~V}$ & $r$ & عبد & 1.9609 & 1 & نهجُر \\
\hline $1196,1.0611 \mathrm{~V}$ & $r$ & راعها & 74.09 & 1 & ينشد \\
\hline
\end{tabular}

ـ صيفة فل:

وردت في سبعة عشر موضعاك، ضمّّت خمسة أفعال، كما في قوله:

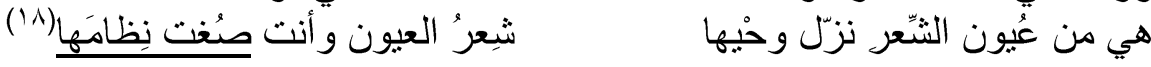




\begin{tabular}{|c|c|c|}
\hline الصفحة & مكرر & القعل \\
\hline 180.01 & - & دُقت \\
\hline 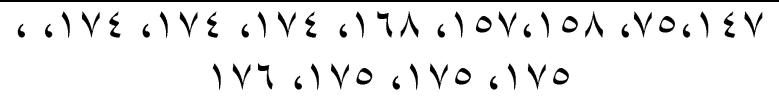 & 11 & قُلت \\
\hline IY & - & رُمت \\
\hline$I V V$ & - & هُرتُ \\
\hline
\end{tabular}

ما حذف عين مضار عه:

استخدم الثناعر الفعلين ( يفُته، تحُل) في موضعين، كما وردا في الصيغة الآتية:

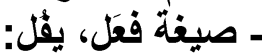

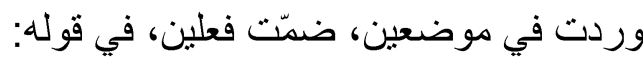

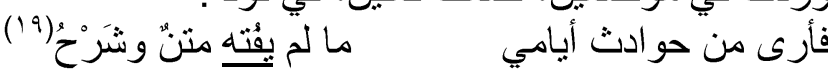
وقوله:

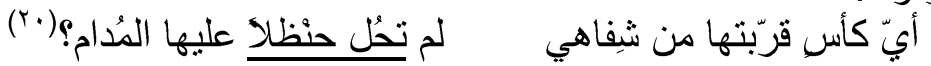
وما حذف لام ماضيه: استخدم الثناعر الفعل كسنت في موضع وامعة واحد، كما ورد في الصيغة الآتية:

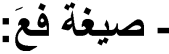

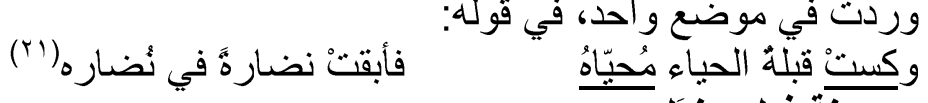

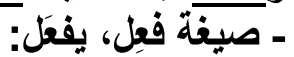

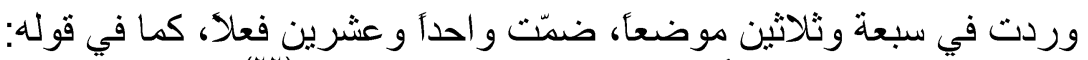

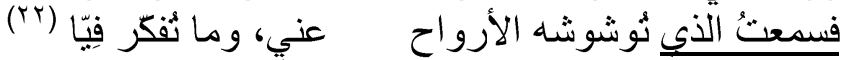
جدول صيغة ( فِلِ، يفعَل) المتعدي

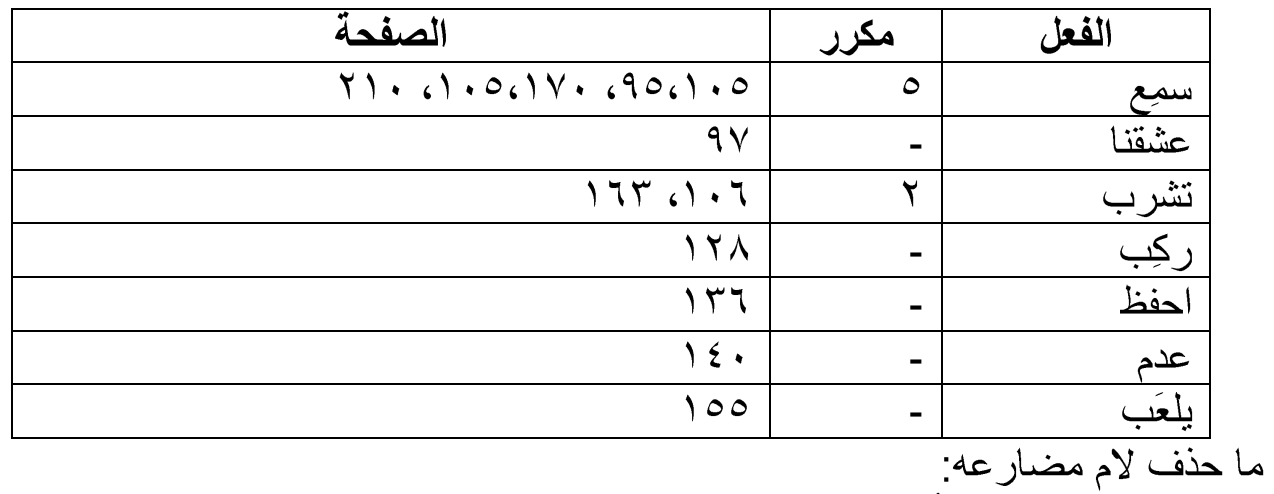

استخدم الثاعر الفعل (ألق))، ورد في موضع واحد، كما في الصيغة الآتية:

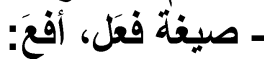

وردت في موضع و احد، في فئه له:

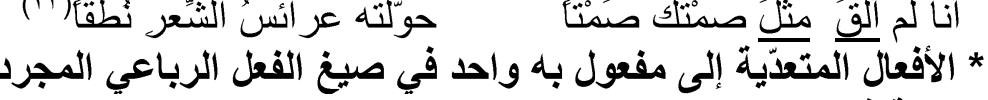
ـ صيغة فعلل: وردت في ثمانية مو اضع ، ضمّلت أربعة أربعة أفعال، كما في قوله:

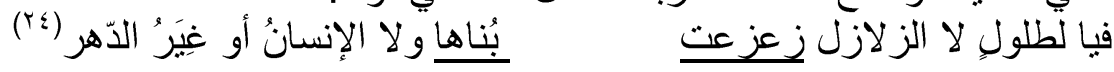




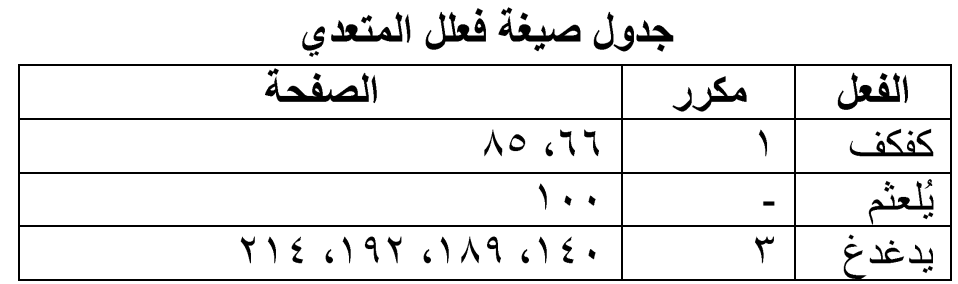

•الأفعال المتعدّية إلى مفعول به واحد في صيغ الأفعال المزيدة:

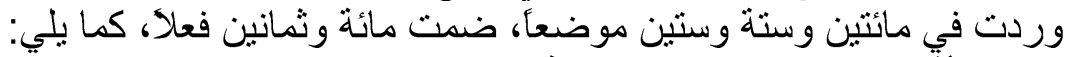

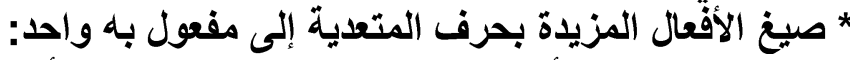

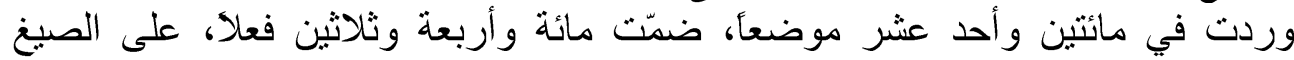
الآتية:

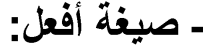
وردت في مئة وثلاثة مو اضع، ضمدّت تسعة وخمسين فعلا، كما في قوله:

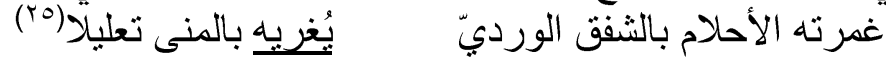
جدول صيغة أفعل المتثدي

\begin{tabular}{|c|c|c|c|c|c|}
\hline الصفحة & مكرر & الفعل & الصفحة & مكرر & الفعل \\
\hline 99 & - & تُذيبها & $Y \ldots 6 \leqslant \Lambda_{6} V Y$ & $r$ & أبعد \\
\hline$V V$ & - & يدير & or ، $\leqslant 0$ & 1 & أنزل \\
\hline 19 & & بُعطي & 199601 & 1 & لُجزي \\
\hline$r \cdot V_{6} \Delta r$ & 1 & يُجيلت & IV9 6АT 671 & r & أبصر \\
\hline 410.97 & 1 & ثتُعش & 71 & - & أناخ \\
\hline 97 & - & أملى & Tr & - & يُريد \\
\hline 986179617967.164 .5 & $\varepsilon$ & أوحى & $7 \varepsilon$ & - & يُنطق \\
\hline $1 \cdot r$ & - & يُر هق & $7 \varepsilon$ & - & تُجيب \\
\hline- & - & - & 70 & - & أحييتها \\
\hline
\end{tabular}
ما حذف عين ماضنيه:

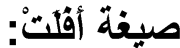

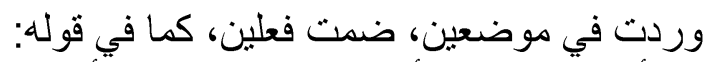

$$
\begin{aligned}
& \text { ور أيت في التاريخ أكبرَ ثلمةٍ } \\
& \text { و أذعتِ آي حجابهِ و عُجابِهِ(rV) } \\
& \text { حتى وقعت لاهن على دفين كنوزه } \\
& \text { ما حذف لام ماضيه: } \\
& \text { - صيغة أفعَ: } \\
& \text { وردت في موضعين، ضمّت فعلا و احدأ، كما في قوله: }
\end{aligned}
$$

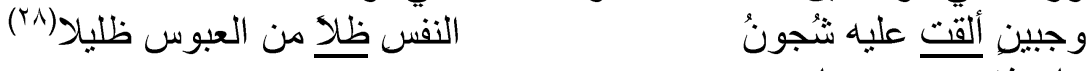

$$
\begin{aligned}
& \text { ما حذف عين مضار عا: }
\end{aligned}
$$

استخدم الثشاعر الفعلين (ثذِبه، وثيثر)، وردا في موضعين، كما في الصيغة الآتية: ـ صيغة أفعل، تُفِل:

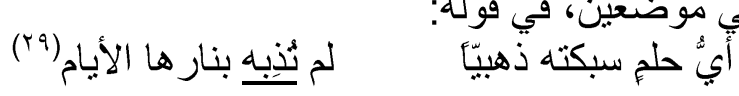




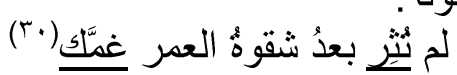

وفي قوله: ما حذف لام مضار عه:

استخدم الثناعر الفعل (تُعطِ)، ورد في موضع واحد، كما في الصيغة الآتية: - ميغة أفعل، يُقع:

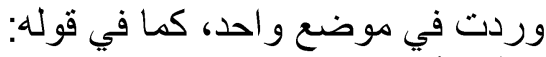

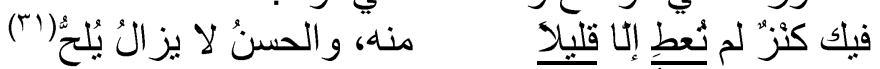

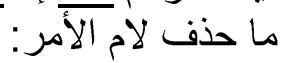
استخدم الثاعر الفعل (أوح)، ورد في موضع واحد، كما في الصيغة الآتية:

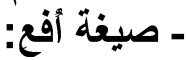

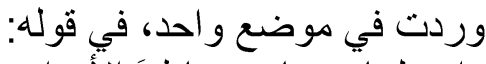

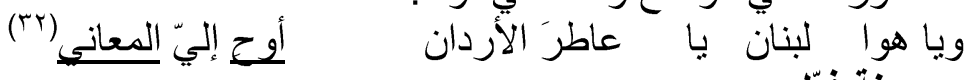

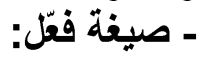
وردت في ثلاثة وسبعين موضعاك، ضمّت اثنين وخمسين فعلا، كما في قوله: إذا بي مابين أجنحة سودٍ

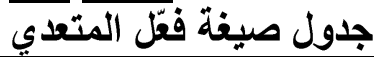

\begin{tabular}{|c|c|c|c|c|c|}
\hline الصفحة & مكرر & الفعل & الصفحة & مكرر & الفعل \\
\hline $7 \leqslant 6110$ & 1 & يُغطي & $V 16 \leqslant \Lambda_{6} 7 V$ & $r$ & قرّب \\
\hline $1 \leq \lambda_{6} \mid 9161 \leq \leqslant 670$ & r & أوشتّيّ & $\varepsilon \wedge$ & - & تُنوّر \\
\hline $7 V_{6} 1 T_{q}$ & 1 & وقع & rIV 6 TA 60Y & $r$ & ذوّب \\
\hline $7 V$ & - & ثُقطع & $0 \leqslant$ & - & يُحيّر \\
\hline $7 V$ & - & يُعكر & 00 & - & لُروضض \\
\hline$\left.\left(7 \Lambda_{6}\right) \cdot V_{6}\right) 71$ & $r$ & يُكلبل & 09 & - & حجّب \\
\hline 71 & - & خطط & $11.6096 \mathrm{~V} .6 \mathrm{VA}$ & $r$ & طوّق \\
\hline
\end{tabular}

وردت في سبعة و عشرين موضعأ، ضمّت واحداً و عشرين فعلا، كما في قوله:

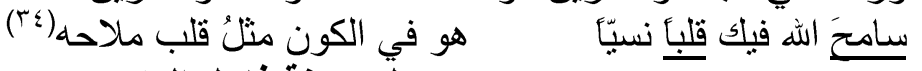
جدول صيفة فاعل المتعدي

\begin{tabular}{|c|c|c|c|c|c|}
\hline الصفحة & مكرر & الفعل & الصفحة & مكرر & الفعل \\
\hline$\Lambda \varepsilon$ & - & أكابد & $17.0 \leqslant$ & 1 & رافق \\
\hline$Y \backslash 1 / 0$ & 1 & يؤاسيني & 71 & - & بحاكي \\
\hline 1.961 .9 & 1 & تواري & 77 & - & يُر اود \\
\hline 111 & - & نر اقب & 199671 & 1 & عانق \\
\hline- & - & - & $V \wedge$ & - & تدافع \\
\hline
\end{tabular}

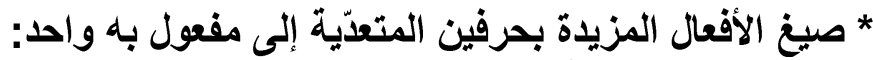

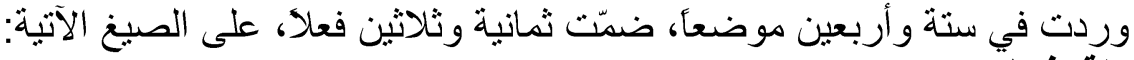
ـ - صيغة افتعل: وردت في اثنين وثناثين موضعاك، ضدّت خمسة و عشرين فعلا، كما في قوله:

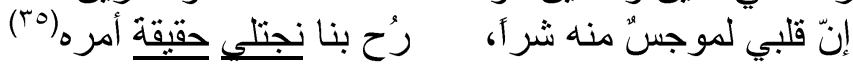




\begin{tabular}{|c|c|c|c|c|c|}
\hline الصفحة & مكرر & الفعل & الصفحة & مكرر & الفعل \\
\hline$V \varepsilon$ & - & انثتقــ & or & - & تتتحي \\
\hline 97 & - & نشتهي & 07 & - & ترتدي \\
\hline$r .969 \mathrm{~V}$ & 1 & نحتسي & $0 \wedge$ & - & نجتلي \\
\hline $1 \ldots$ & - & أنثتاقه & $V 96 \leqslant V$ & 1 & اختار \\
\hline 1.1 & - & انتقد & $1 \mathrm{VV}_{6} 1.1 .9 V_{6} \mathrm{~V}$. & $r$ & احتوى \\
\hline 111 & - & نلتحف & $V T$ & - & يمتصّ \\
\hline
\end{tabular}

ـ صيغة تفقّل:

وردت في أربعة عشر موضعاك، ضمّت ثناثثة عشرَ فعلا، كما في قوله:

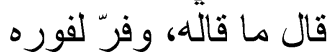

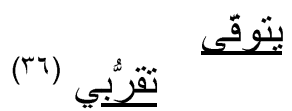

\begin{tabular}{|c|c|c|}
\hline الصفحة & مكرر & الفعل \\
\hline 79 & - & تتسّم \\
\hline Vo & - & يتوّقى \\
\hline$V V$ & - & تَأخّر \\
\hline 99 & - & تتصبّد \\
\hline 117 & - & تفحسص \\
\hline 119 & - & تألث \\
\hline 178.178 & 1 & تعثدّق \\
\hline 170 & - & تمنّى ت \\
\hline
\end{tabular}

صيغ الفعل المزيد بثلاثة أحرف المتعدّي إلى مفعول به واحد:

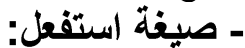

وردت في تسعة مو اضع، ضمّت ثمانبة أفعال، كما في قوله:

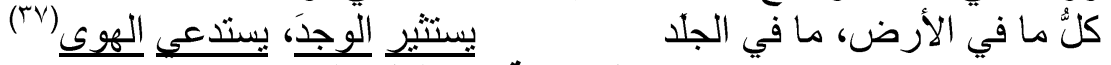
جدول صيغة (استفعل) المتعدي لونيتي

\begin{tabular}{|c|c|c|}
\hline الصفحة & مكرر & الفعل \\
\hline $0 \wedge$ & - & بستعمر \\
\hline $11 \mathrm{~V} 671$ & 1 & يستعيد \\
\hline 1.1 & - & استعذب \\
\hline 111 & - & يستهون \\
\hline 119 & - & استخار \\
\hline$V \varepsilon$ & - & استرجع \\
\hline
\end{tabular}

• القسم الثاني :الأفعال المتعديّة إلى مفعولين:

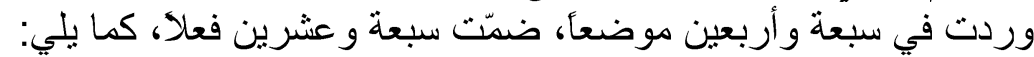
ـ صيغ الفقعل المجرد المتعدّي إلى مفعولين:

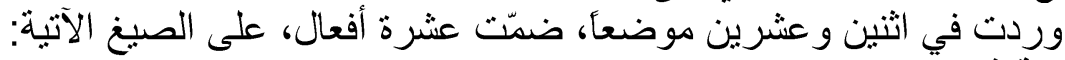
ـ صيغة فعلَ، يفعلَ: وردت في تسعة مواضع، ضمّتّ أربعة أفعال، كما في قوله: 


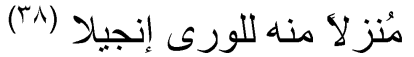

جدول صيغة (فعل ، يفعل) المتعدى لمفعولين

ملاِ العالِِ السماويّ شدوَاَ

\begin{tabular}{|c|c|c|}
\hline الصفحة & مكرر & القعل \\
\hline 6$) 51679$ & - & ملأ \\
\hline 171615.6117690690 & 0 & خال \\
\hline $1 \cdot \varepsilon$ & - & وضع \\
\hline 171 & & أرى \\
\hline
\end{tabular}

ما حذف عين ماضيه :

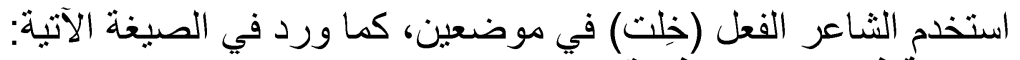

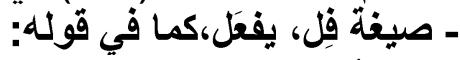

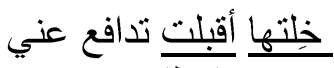

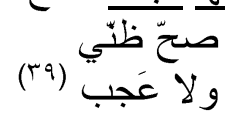

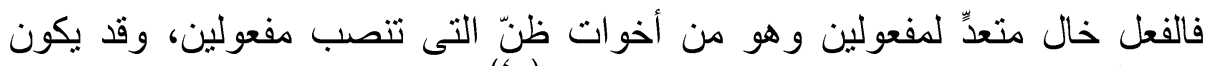

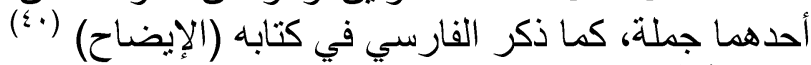

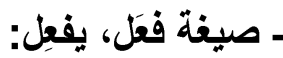

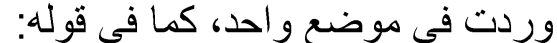

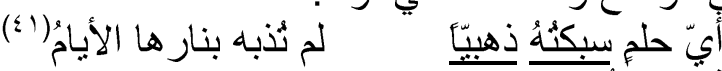

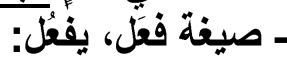
وردت في ثلاثة مو اضع، ضمّت ثلاثة أفعال، كما في قوله:

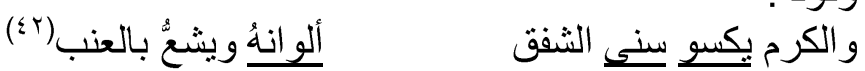
وقوله: وردي

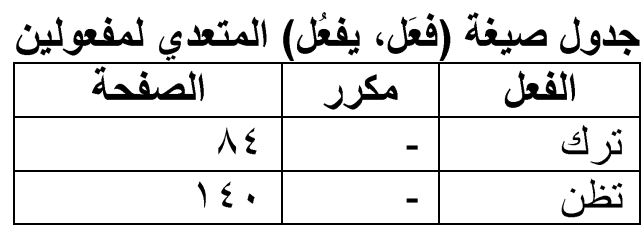

ما حذف لام ماضيه: استخدم الثناعر الفعلين (دعَوه، كست) في خمسة مو اضع، كما ورد في الصيغة الآتية:

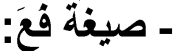

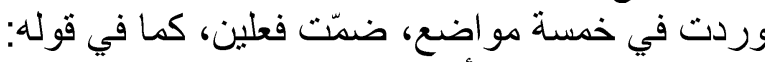

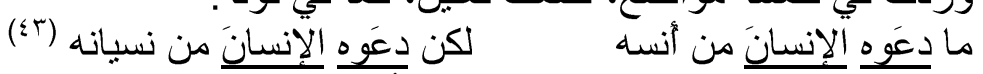

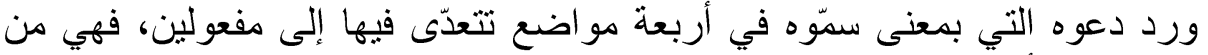

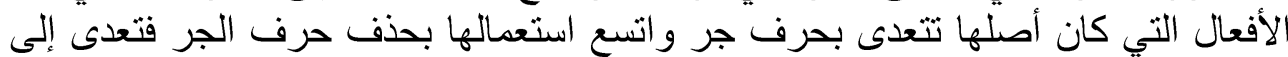

\begin{tabular}{|c|c|c|}
\hline \multicolumn{3}{|c|}{ ول صيغة (قُع) المتعدي } \\
\hline الصفحة & مكرر & الفعل \\
\hline 177689 & 1 & دعوه \\
\hline $1 \varepsilon$. & - & كست \\
\hline
\end{tabular}
مفعولين. 


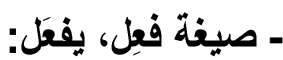

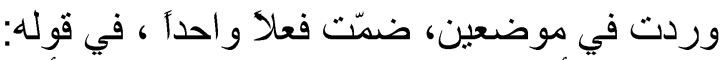

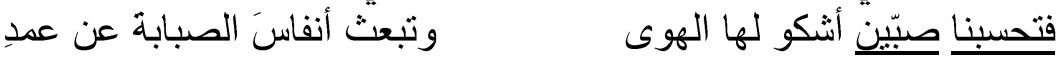

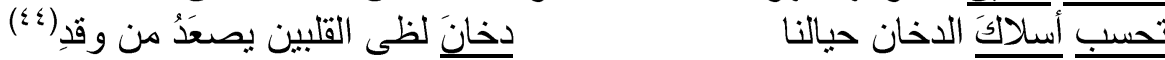

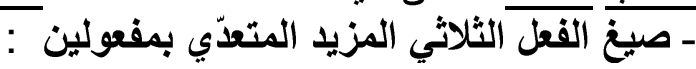

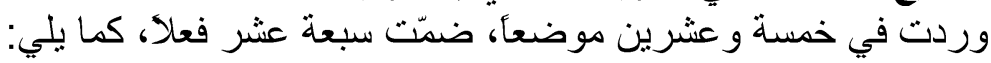
* صيخ الفعل المزيد بحرف:

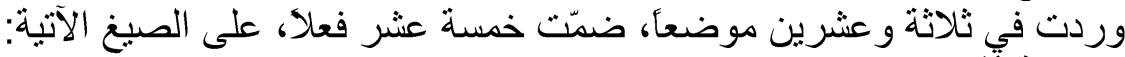
ـ صيغة أَفعل: وردت في أنثى عشر موضعاً تتعدّى فيها إلى مفعولين، ضمّت ثمانية أفعال، كما في قوله:

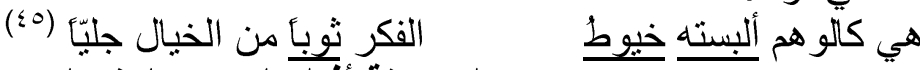
جدول صيفة أفعل المتعدي لمفعولين

\begin{tabular}{|c|c|c|}
\hline الصفحة & مكرر & القعل \\
\hline $1 \wedge \varepsilon 6 \vee 7$ & 1 & أعطي \\
\hline$\Lambda$. & - & يُنسيه \\
\hline $1 \cdots$ & - & يُلهمك \\
\hline $1 \ldots$ & - & أمحضـه \\
\hline 171.10761 .1 & $r$ & ألبس \\
\hline Irr & - & أو لاك \\
\hline ITA & - & تُهي \\
\hline Y. T & - & أورثثلك \\
\hline
\end{tabular}

ما حذف عين ماضبيه: استخدم الثناعر الفعل (أرتنا) في موضع واحدة، كما ورد في الصيغة الآتية: ـ صيغة أفقلَ:

أرنتا منه حقبقة ذاته (T؛ وردت في موضع و احد، في قوله:

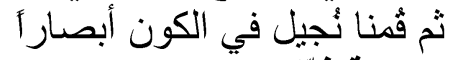

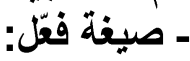
وردت في عشرة مو اضع، ضمّت ستة أفعال، كما في قوله: لنودّع أنفاسه ونداها جدول صيغة فِّل المتعدي لمفعولين

\begin{tabular}{|c|c|c|}
\hline الصفحة & 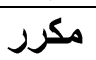 & الفعل \\
\hline 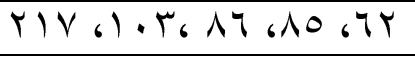 & $\varepsilon$ & حوّل \\
\hline 1.1 & - & حمّل \\
\hline 179 & - & 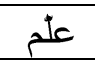 \\
\hline 198 & - & أسلمه \\
\hline$r \cdot r$ & - & يسميّيه \\
\hline
\end{tabular}


استخدم الثاعر صيغة واحدة وهي افتعل، وردت في موضع واحد، ضمّتّ الفعل (اتخذ)،

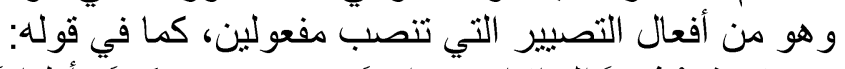

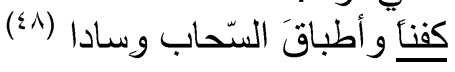

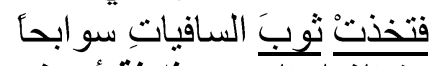
* صيغ الفعل المزيد بثلاثة أحرف:

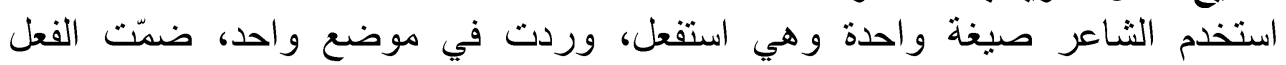

$$
\text { (بستنزل)، في قوله: }
$$

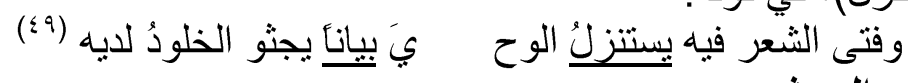
نتائج البحث:

• استخدم الثاعر الأفعال المتعدية لففعول واحد ، كما استخدم الأفعال المتعدية لفععولين.

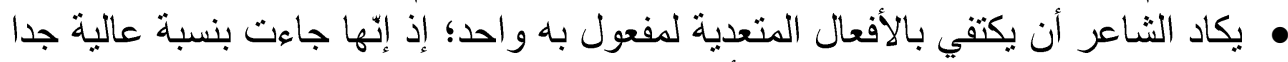

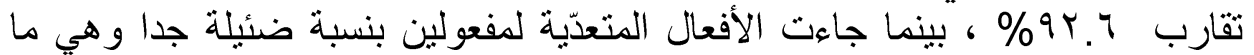

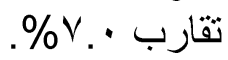

• • لم ترد الأفعال المتعدية لثلاثة مفاعيل.

• و افقق فوزي المعلوف في استخداماته لصنيغ الأفعال المتعدية ما ورد في كتب الصرف،

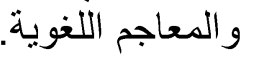


Abstract

The structures of transitive verbs in Fawzi Al-Maalouf's Diwan

By Amani Ahmed Mahmoud

This research is based on the description of the structures of vertebrate verbs in Fawzi Al-Maalouf's library, and the statement of the poet's compatibility with what was reported with the linguists. This is done by statistical studies with the presentation of evidence from the Bureau.

This is classified in a study:

1. Formulas of abstract vertebrates for a single object.

2- Formulas of abstract vertebrates for operators.

3 - Formulas of hyperbolic acts of a single object.

4- Formulas of hyper-verb conjugation.

As for the study of the formulas of the transverse acts of three elements, they were not classified with the previous versions, because they were not found in the poet's library.

\section{الهوامش}

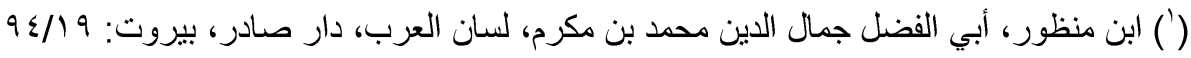

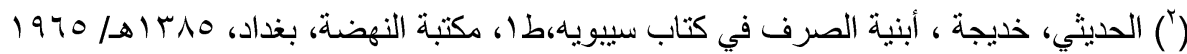

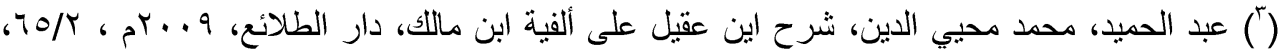

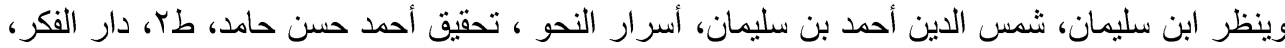

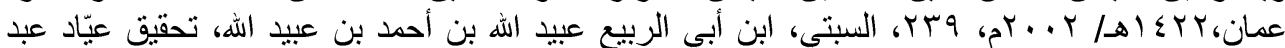

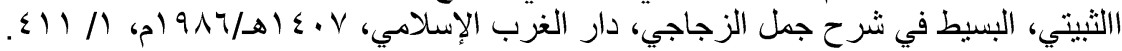

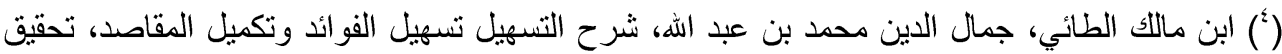

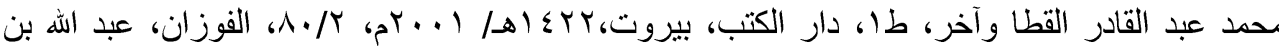

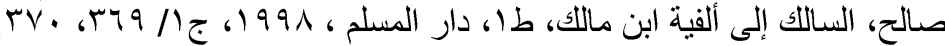

(') ابن قتبر، عمرو عثمان (سييويد)، الكتاب، تحقيق عبد السلام هارون ، مكتبة الخانجي، القاهرة ، طب،

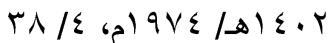

(") ابن جني، أبو الفتح عثمان ، اللمع في العان العربية، تحقيق: د. سميح أبو مغلي، دار مجدلاوي، عمان،

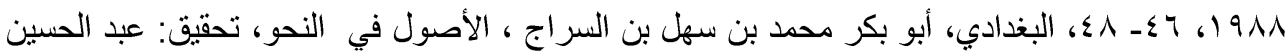

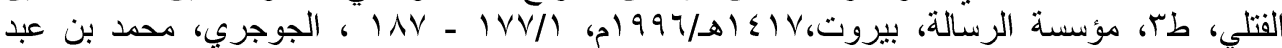

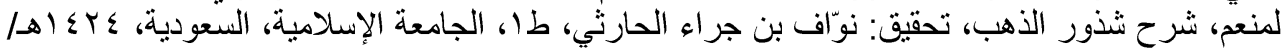

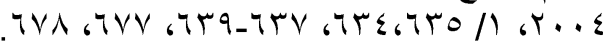

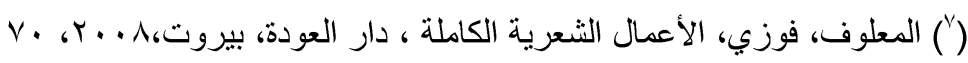

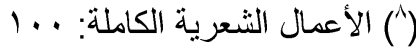

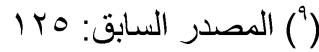

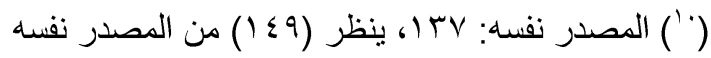

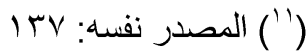

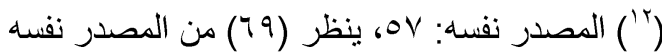

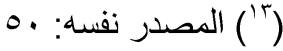




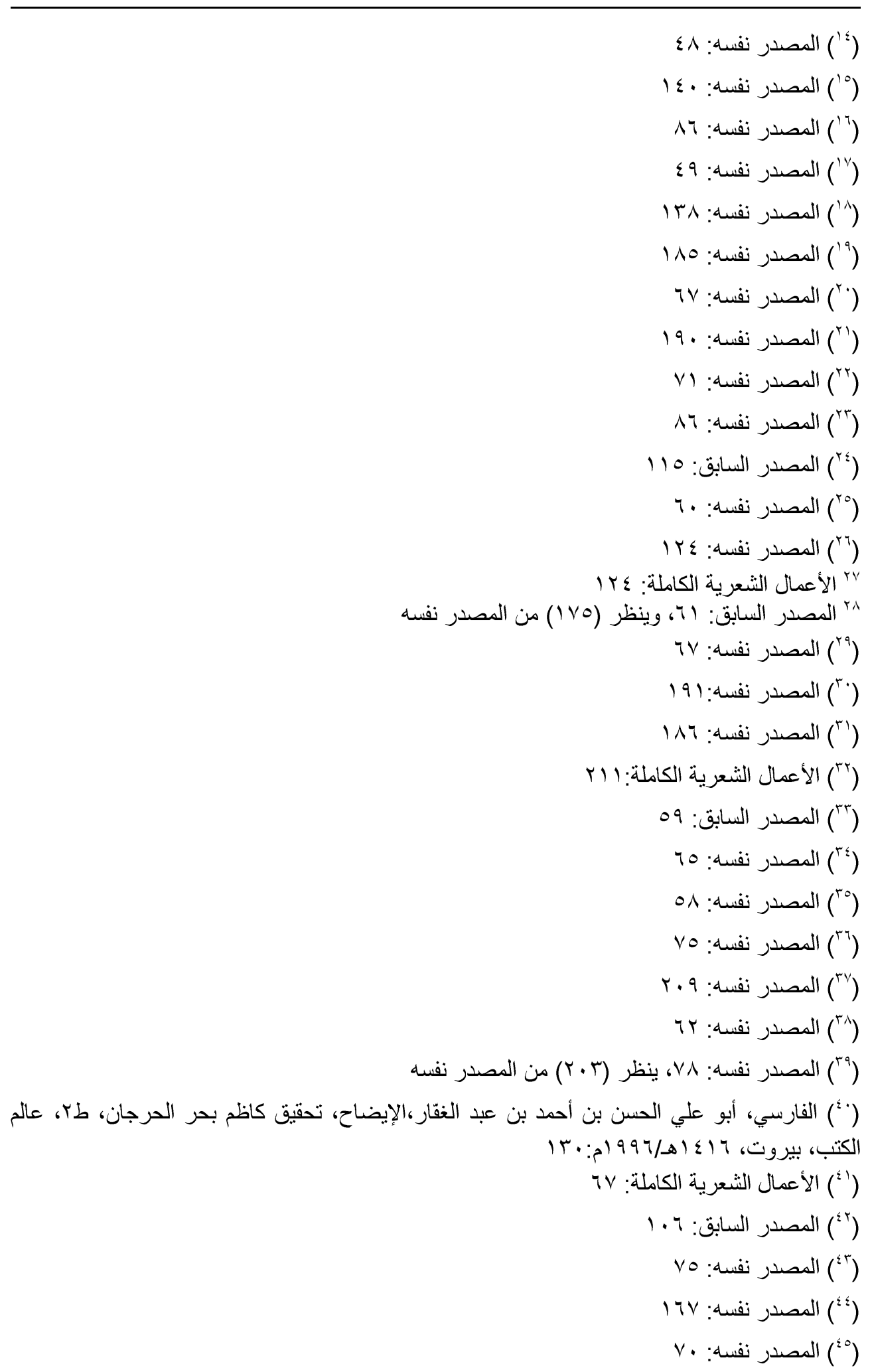




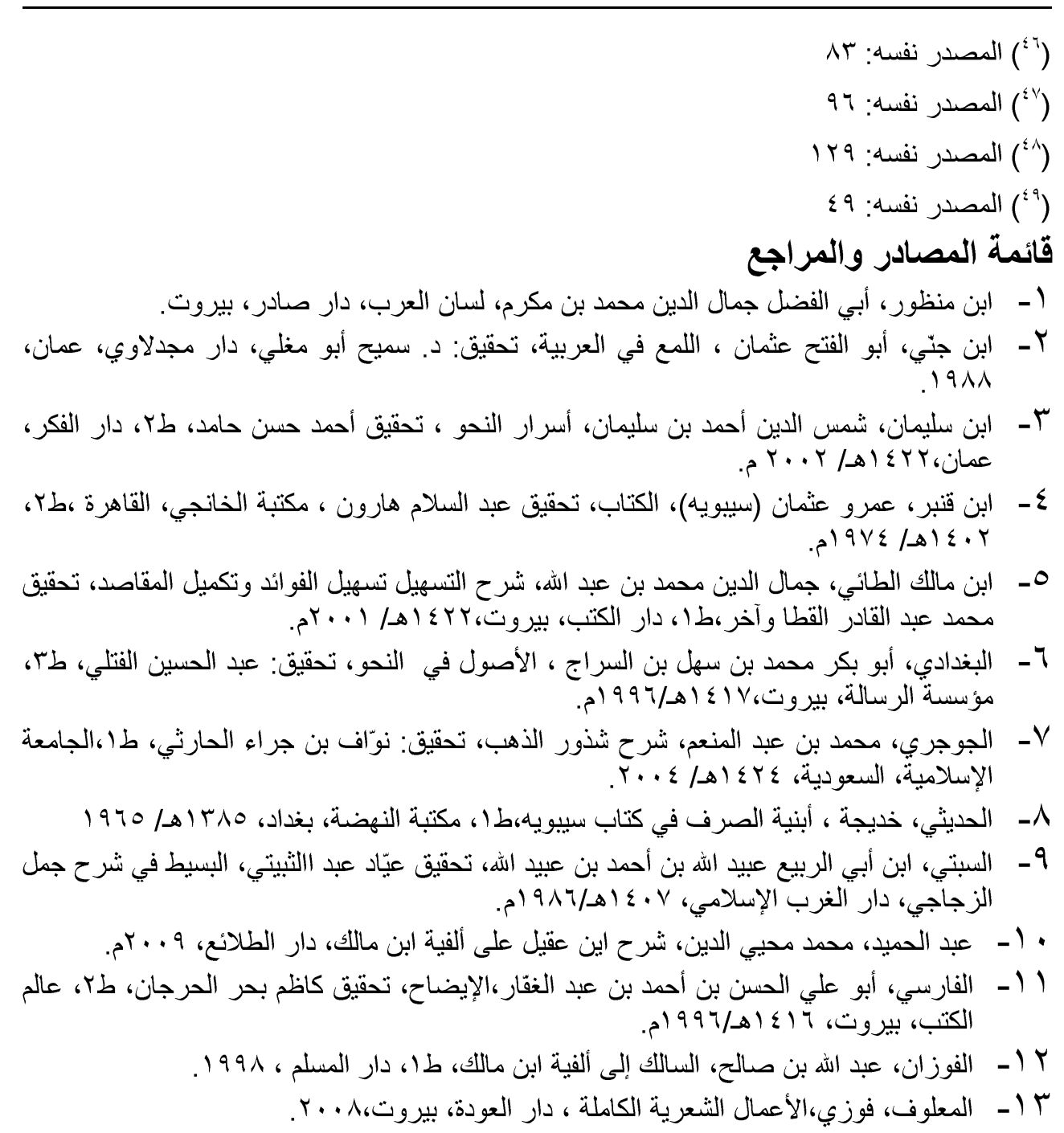

